\title{
Capacity and scale inefficiency: Application of data envelopment analysis in the case of the french seaweed fleet
}

\author{
Guyader Olivier ${ }^{1}$, Daures Fabienne ${ }^{1}$ \\ ${ }^{1}$ Ifremer, Centre de Brest, France \\ * Corresponding authors : Olivier Guyader, email address : oguyader@ifremer.fr and Fabienne Daures, \\ email address : fdaures@ifremer.fr
}

\begin{abstract}
:
Data Envelopment Analysis (DEA) models are applied to the main French seaweed fleet to examine capacity output, capacity utilization, and scale inefficiency. Coastal seaweed vessels target only one output - kelp - with the same gear but with different input level combinations. The fishery is seasonal and subject mainly to input regulations, especially a one trip per day regulation implemented in 1987. The consequence was a decline in total observed output and a fall in capacity output and efficient output. Only the largest vessels and a few small vessels harvesting without this regulatory constraint operate at the optimal scale. The question of a change in regulation, especially a shift to an individual quota system, is raised.
\end{abstract}

Keywords : Data Envelopment Analysis, capacity, capacity utilization, scale in- efficiency, production frontier, seaweed, fleet

JEL classification : Q22

The authors are grateful to the two anonymous referees for their comments and suggestions. 


\section{Introduction}

There is increasing concern about excess capacity at an international level, as well as in the European Union (Gréboval and Munro 1997; Hatcher and Robinson 1998). As underlined by Gordon (1954), excess capacity of harvesting fleets results from the lack of definition of rights to common-pool resources, the resulting absence or imperfection of markets for them, and the externalities that it entails. Excess capacity of fishing fleets has also led to adverse effects on fishing stocks, reducing the biological productivity and the economic performance of the fleets in many fisheries throughout the world. In order to control and reduce the harvesting capacity of fleets, fisheries managers have implemented different policy options based either on the control of the level of the catches (Total Allowable Catches) or administrative programs aiming at reducing the size of fleets or both. In many cases, public policies have considered capacity as inputs into the production process, especially within the Common Fishery Policy of the European Union where each member state has to fulfil fleet size reduction objectives expressed in terms of vessels' physical parameters (Holden 1994) (Frost et al. 2001). As underlined by Kirkley and Squires (1999), there is not a unique definition or measurement of capacity in the fisheries field. However, in economic theory, capacity is defined in terms of output-based measures. Capacity and capacity utilization are important concerns for fisheries management and it is crucial to assess their current levels in order to determine the reduction in capacity required to reach objectives established by management authorities.

The Data Envelopment Analysis (DEA) approach is one of the methods used to determine harvesting capacity. DEA is a non-parametric approach applied to problems in which answers about optimum input levels or output levels and their characteristics are desired. The main methodological issues were addressed by Charnes, Cooper and Rhodes (1978), Färe, Grosskopf and Lovell (1985), Coelli, Rao and Battese (1999).

Charnes et al. (1995) and Färe, Grosskopf and Lovell (1994) provide a comprehensive discussion of DEA models and their two primary orientations. The input-based measure indicates the level by which inputs may be changed to best harvest a given output level. The output-based efficiency measure determines by how much output can be expanded or changed given the available level of inputs. It allows managers to identify the level of output and subsequent vessels which would maximize output, subject to given input levels and resource constraints. The output-orientated DEA model is provided hereafter and the framework of Färe, Grosskopf and Lovell (1994) is utilized. Färe, Grosskopf and Kokkenlenberg (1989) proposed that the DEA framework could be modified in order to estimate capacity as defined by Johansen (1968). Capacity estimate then refers to the maximum potential or frontier level of output that could be produced given the fixed factors and full utilization of the variable factors. The

DEA technique assesses the capacity output scores of an existing technology relative to an ideal, "best practice", frontier technology (Coelli, Rao and Batteese 1999). That is, the output is as large as possible given input and technology levels, or the input levels are as small as possible given the output levels (Färe et al. 2000).

The objective of this paper is to measure capacity output, capacity utilization and scale inefficiency of the seaweed fleet operating in French coastal waters (Brittany region) and to try to analyze the impact of regulatory measures, especially the trip regulation. The technology of vessels harvesting one output (seaweed) with one gear can be considered as relatively easy to represent and study. The fishery is seasonal and the fleet mainly regulated on the input side by a licence system with a 
numerus clausus and by constraints on the number of authorized trips per day. The paper attempts to assess the maximum amount of output each fishing unit or fleet can produce given available input stocks. Beyond the classical analysis of capacity utilization, the paper also focuses on the question of scale efficiency addressed by Cooper, Seiford and Tone (2000). The results presented hereafter were produced within a European project dealing with the DEA methodology applied to the fishing industry (Vestergaard et al. 2002).

The first part of the paper describes the fishery and focuses on the capacity related problems encountered. The common methodology developed is presented with specific focus on the question of scale efficiency. The data set used is presented and sensitivity analysis on the number of fixed inputs is carried out in order assess the sensitivity of the capacity utilization (CU) scores. The conclusion is that there is an increasing return to scale in the seaweed fishery. Regulating the authorized number of trips per day has promoted this situation and the seaweed fleet is now composed of a greater percentage of larger vessels. The level of capacity utilization is high and there is a relatively low possibility of output capacity improving with an increase in activity. 
In France, the main seaweed fishery is located in the Brittany region and most of the fields harvested are located in the western part of this area. The fishery is seasonal - from May to October - and the vessels are either specific vessels or fishing units also operating in scallop fisheries during winter. In 1999, the fleet was composed of 57 small-scale vessels with the following average technical characteristics in terms of length (9.58 meters), tonnage (10.25 GRT) and engine power $(67 \mathrm{~kW})$. They differ from other vessels by their relative bigger storage or hold capacity (15.7 cubic meters) to carry seaweed from the fishing areas to the main harbors. The only seaweed species targeted is called kelp (laminara digitata) and vessels are fitted out with a specific gear to harvest it: a hydraulic crane with a hook. Landings are mainly sold to the processing industry in order to produce colloids. The price of kelp is negotiated each year and for the entire season between fishermen organizations and processors. This analysis of the deflated price of kelp shows that it has been roughly the same over the last fifteen years $(38 € /$ ton). This means that we can exclude price effects of kelp on fishermen's behavior.

The fleet is managed by an individual license system (numerus clausus) with regulations on vessel characteristics, especially the maximum length authorized to enter the fishery. The number of trips per day was also limited to one in 1987, in order to reduce the fishing nominal effort. This regulation is still in force at present. Since 1999, the regulating authority has decided to ration the number of days at sea per vessel at the beginning of the season. In 2000, regulators also decided to implement a Total Allowable Catches per month in order to better regulate landings. The objective was to reduce kelp mortality and therefore benefit from the intra-annual growth of seaweed biomass which is linked to the increase in sunlight. Finally, kelp biomass is controlled by the first winter storms that lead to a complete natural depletion of seaweed fields. The level of exploitation is mainly influenced by the evolution of kelp abundance, alternatives in other fisheries for multipurpose vessels, and meteorological conditions. Nominal effort, expressed in terms of days at sea, is limited at the beginning of the season due to sea conditions. As shown in the next figure, the level of days at sea for the fleet increases between May and July when the catch per unit of effort is at its highest level. The number of vessels involved in the seaweed fishery declines in September as and when the abundance of the stock plummets.

Figure 1. Seasonality of the Exploitation (Years 1997-1998-1999)

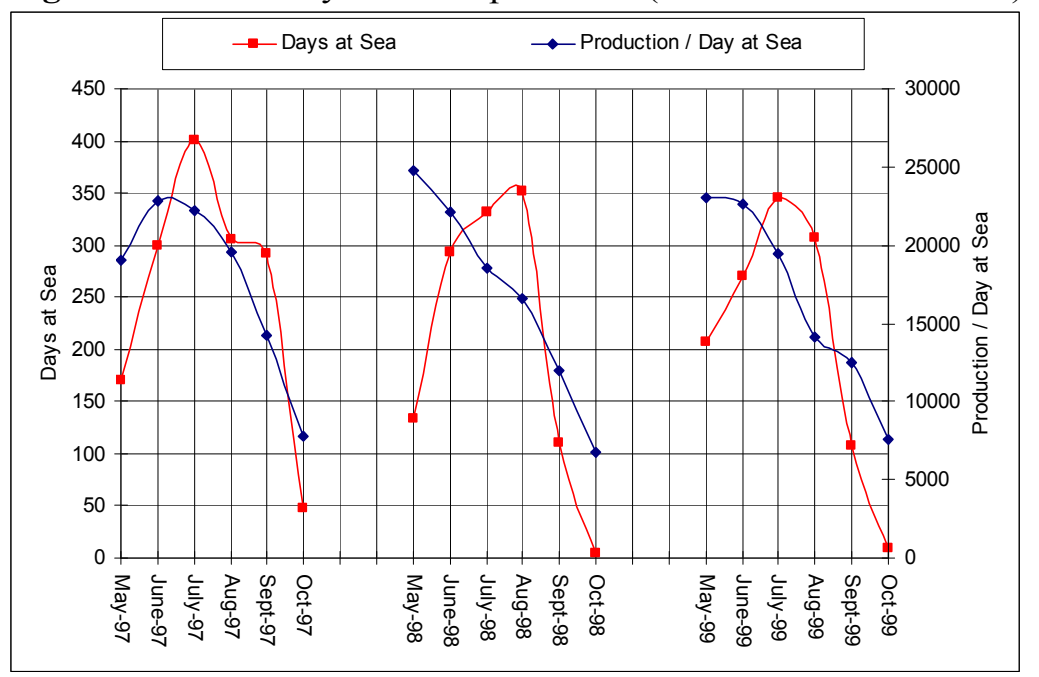

Source: Ifremer 
The fishery ends in October with the arrival of the first storms and bad sea conditions for such small-scale fishing units.

\section{Evolution of the Fishery and Capacity Related Problems}

The average production of the fishery has been about 60,000 tons per year over the last fifteen years. However, landings have declined due to a combined reduction in the number of active vessels and in the biomass level (Figure 2, 3). Figure 3 describes the evolution in kelp abundance indexes through two indexes, the number of kelp plants and total weight and per square meter, respectively. Despite inter-annual variability in resource abundance, a declining trend in biomass indexes - from 7 to $4 \mathrm{~kg} / \mathrm{m}^{2}$ - appeared between 1989 and 1999. An about-turn seemed to occur in 2000 and 2001, and a shift in environmental conditions, especially water temperature, seems to be responsible for these changes.

Figure 2. Evolution of the Number of Vessels and their Landings

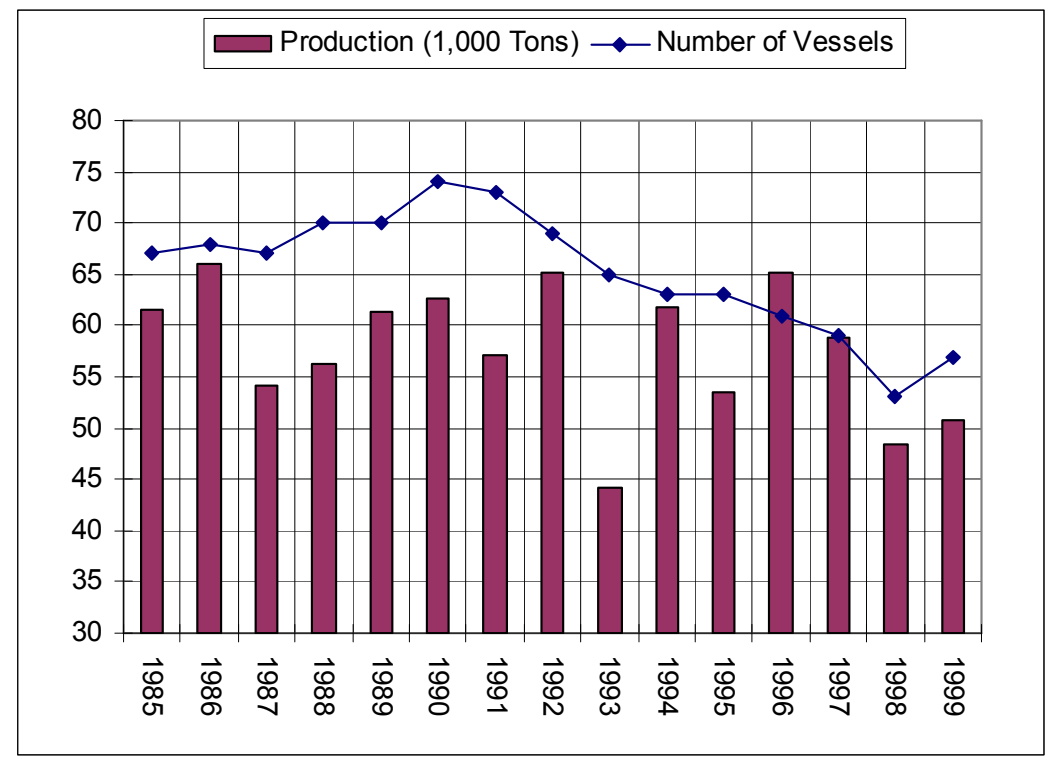

Source: Ifremer and Administrative Data 
Figure 3. Evolution of the Biomass Index per Year (Main Area)

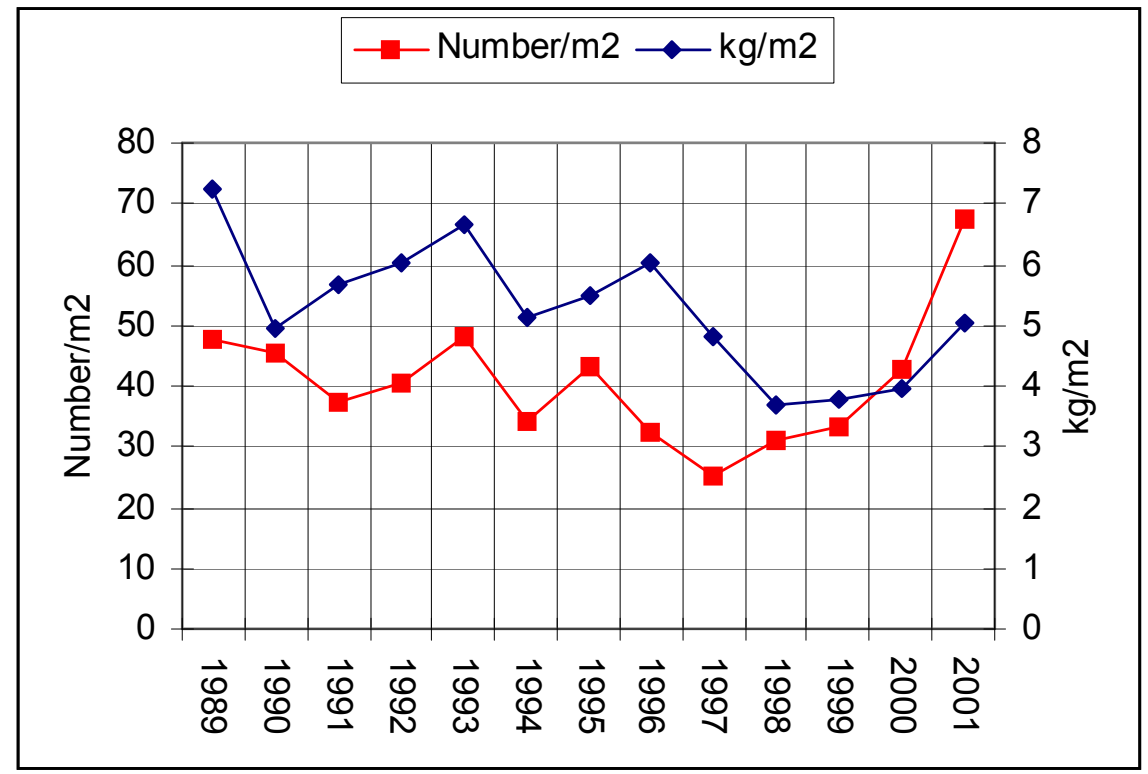

Source: Ifremer

The main economic problem for the fleet is the excess investment that occurred at an individual level through the mechanization of vessels and an increase in hold capacity of the fishing units (Arzel 1998). Despite a reduction in vessel numbers, total engine power increased at the end of the 80 's, then stabilized in the 90's. Fishermen increased their levels of inputs by operating changes in the vessels' configuration. This is a classical phenomena of input substitution within license systems analyzed by Townsend (1985). As a consequence, average engine power grew by about $42 \%$ between 1985 and 1999, but length did not increase because of regulations on vessel size limits. As many vessels operate in scallop fisheries, a significant proportion of the increase in physical inputs can be ascribed to the competition within these fisheries. Figures 4 and 5 depict the evolution of the main characteristics of the fleet, and number of vessels and landings, respectively. 
Figure 4. Evolution of the Main Average Characteristics of the Fleet

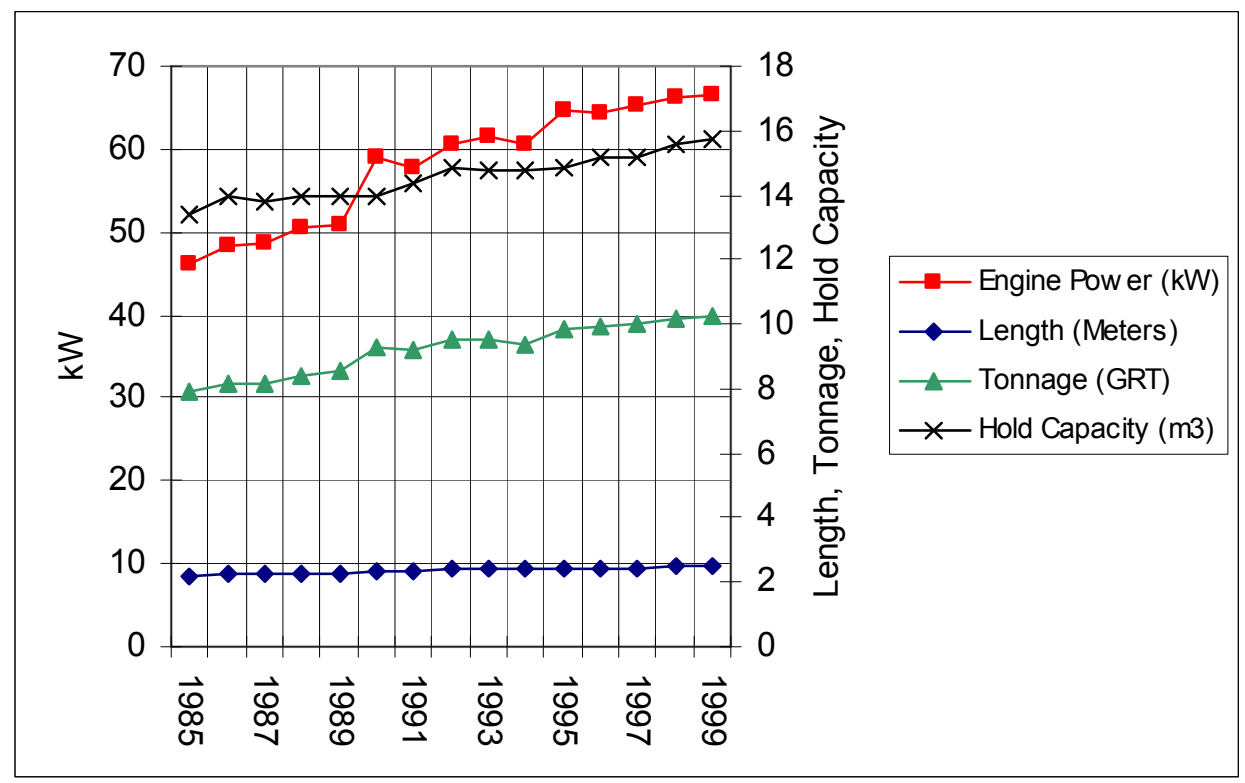

Source: Ifremer

Figure 5. Evolution of Fleet Engine Power and Production per Vessel

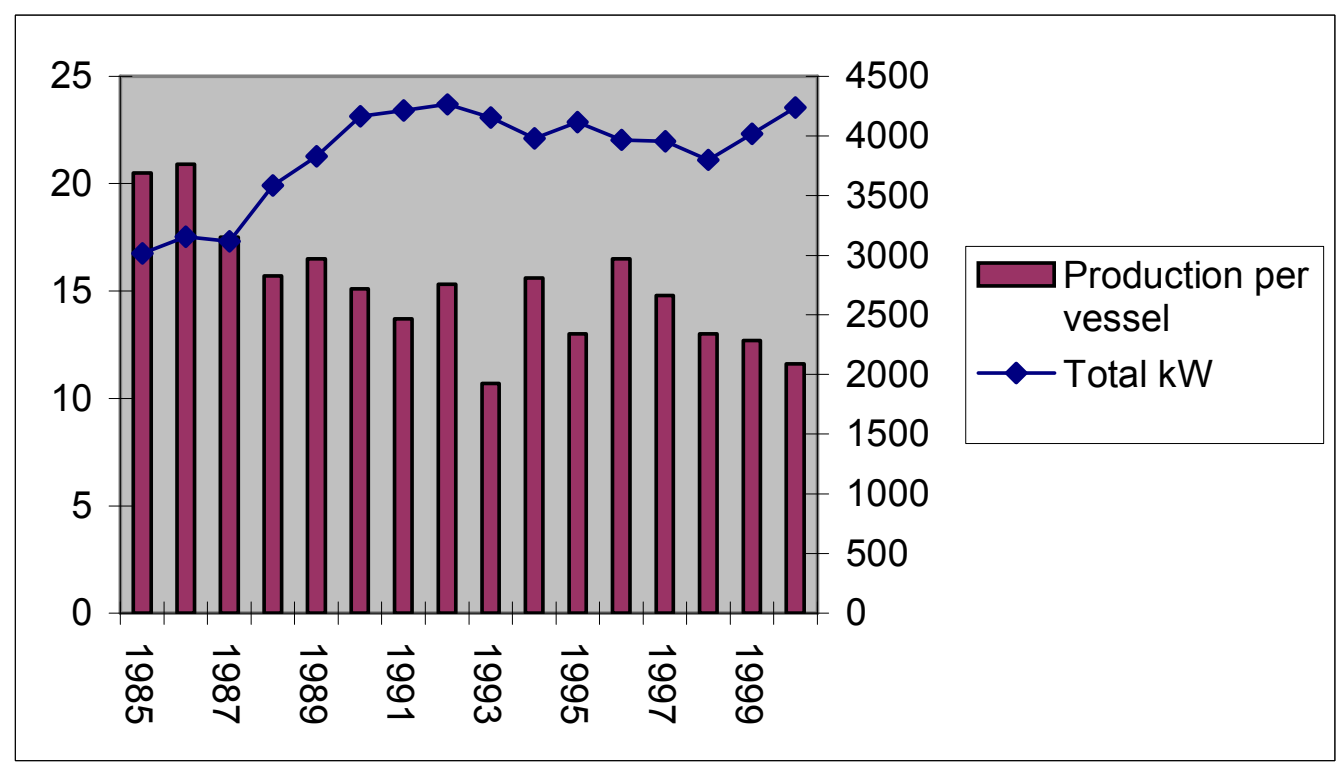

Source: Ifremer

A natural decline in stock abundance partly explainsthe decline in individual landings, but overcrowding in the fishing area and overexploitation of the growth of kelp has reduced individual landings. On the other hand, the increase in the size of the average vessel has probably led to a reduction in the accessibility to specific areas for the largest vessels. 


\section{Specifications of the Data Envelopment Analysis Models}

The DEA Models used in this paper were carried out within a European Research Project with the aim of developing a common methodology for selected European fleet (Vestergaard et al. 2002). Färe et al. (1989) proposed a formal statement and proof of Johansen's plant capacity (1968) using an output-orientated technical efficiency model. The model holds fixed inputs constant and determines the maximal output that can be produced for any given level of fixed input. The approach provides a scalar measure or efficiency score, $\theta^{*}{ }_{1}$, that indicates the percentage by which the production of each output of each vessel may be increased. That is, the score measures the distance between the observed output and the 'best-practice' frontier.

\section{Capacity Output and Capacity Utilization}

The estimation of capacity output can be obtained by solving a linear programming model. We designate the vector of outputs by $u$ and the vector of inputs by $x$, with $m$ outputs, $n$ inputs, and $j$ vessels or decision making units. Inputs are divided into fixed factors, defined by the set $F_{x}$, and variable factors defined by the set $V_{x}$. The capacity model considers unrestricted use of the variable inputs. Capacity output and the optimum or full input utilization values require us to solve the following problem:

$\operatorname{Max}_{\theta, z, \lambda} \theta_{1}$

subject to:

$\theta_{1} u_{j m} \leq \sum_{j=1}^{J} z_{j} u_{j m}, \quad \forall m$

$\sum_{j=1}^{J} z_{j} x_{j n} \leq x_{j n}, \quad n \in F_{x}$

$\sum_{j=1}^{J} z_{j} x_{j n}=\lambda_{j n} x_{j n}, \quad n \in V_{x}$

$z_{j} \geq 0, \quad \forall j$

$\lambda_{j n} \geq 0, \quad n \in V_{x}$

where:

$\theta_{l}$ is the capacity score,

$u_{j m}$ is the amount of output $m$ produced by vessel $j$,

$x_{j n}$ is the quantity of input $n$ used by vessel $j$,

$z_{j}$ is the intensity variable for vessel $j$,

$\lambda_{j n}$ is the input utilization rate by vessel $j$ of variable input $n$.

The problem imposes constant returns to scale (CRS) and it is assumed that each producer uses nonnegative amounts of each input to produce non-negative amounts of each output. The objective of this method is to assess the so-called global technical efficiency of the fishing units and the consequence of imposing constant returns to scale is that the supporting hyperplane does have to pass through the origin. Equation (2) represents one constraint for each output, while equation (3) constrains the set of fixed factors. Equation (4) allows the variable inputs to vary in order not to constrain the model. Equation (5) is the non-negativity condition on the $z$ variable. The $z$ vector 
allows us to decrease or increase observed production activities (input and output levels) in order to construct unobserved but feasible activities. The vector also provides weights that are used to construct the linear segments of the piece-wise, linear frontier technology constructed by DEA.

The model is run once for each vessel in the data set. Capacity output is then determined by multiplying $\theta^{*}{ }_{1}$ by the observed output. This is consistent with the Johansen (1968) definition of capacity because only fixed factors constrain production (Walden and Kirkley 2000b).

Capacity utilization $(\mathrm{CU})$ can be calculated using the observed output as follows:

$C U($ observed $)=\frac{u}{\theta_{1}^{*} u}=\frac{1}{\theta_{1}^{*}}$

This measure provides a ray measure of capacity output and CU in which the multiple outputs are expanded in fixed proportions relative to their observed values (Segerson and Squires 1990). This corresponds to a Farrell (1957) measure of output-orientated technical efficiency due to the radial expansion of outputs, as the ray measure converts the multiple-output problem to a single-product problem by keeping all outputs in fixed proportions. The CU scores range from 0 to 1 , with 1 representing full capacity utilization. Values of less than 1 indicate that the vessel is operating at less than full capacity given the set of fixed inputs.

However, the observed measure of CU might be downwards-biased, because the numerator in the measure, the observed outputs, may not necessarily be produced in a technically efficient manner (Färe, Grosskopf and Lovell 1994). A technically efficient measure of outputs can be obtained by solving a problem where both the variable and fixed inputs are constrained to their current levels. The outcome $\left(\theta^{*}{ }_{2}\right)$ shows the amount by which production can be increased if production is technically efficient. Färe, Grosskopf and Lovell (1994) indicate that this can be determined by solving another linear programming problem, which is similar to the second capacity problem:

$\operatorname{Max}_{\theta, z} \theta_{2}$

subject to:

$\theta_{2} u_{j m} \leq \sum_{j=1}^{J} z_{j} u_{j m}, \quad \forall m$

$\sum_{j=1}^{J} z_{j} x_{j n} \leq x_{j n}, \quad n \in F_{x}$

$\sum_{j=1}^{J} z_{j} x_{j n} \leq \lambda_{j n} x_{j n}, \quad n \in V_{x}$

$z_{j} \geq 0, \quad \forall j$

The difference between the first model and this second model is that variable inputs are unconstrained and constrained to their current level, respectively. The CU efficient measure is then calculated as the ratio of the technically efficient output $\left(\theta_{2}^{*}\right)$ multiplied by the observed production for each output) and capacity output, that is: 
$C U($ efficient $)=\frac{\theta_{2}^{*} u}{\theta_{1}^{*} u}=\frac{\theta_{2}^{*}}{\theta_{1}^{*}}$

The technically efficient CU measure or "Färe" CU measure again ranges from 0 to 1 . Values less than 1 indicate that $\mathrm{CU}$ is less than full $\mathrm{CU}$, even if all current inputs (variable and fixed) were used efficiently.

Färe et al. $(1989,1994)$ also introduced the concept of using the DEA approach to provide information on the optimal utilization rate of variable inputs, $\lambda_{j n}^{*}$, or the utilization of the variable inputs required for production at full capacity output. For example, if the ratio of the optimal variable input level and the observed variable input level exceeds 1.0 in value, then there is a shortage of the $i^{\text {th }}$ variable input currently employed and the vessel should expand the use of that input. Based on the capacity problem using DEA, we can thus obtain a measure of observed input to optimum input, or the input level corresponding to full capacity utilization or capacity output, as follows:

$\lambda_{j n}^{*}=\frac{\sum_{j=1}^{J} z^{*} x_{j n}}{x_{n}} ;$

where $n$ pertains to variable inputs of the $j^{\text {th }}$ producer and $z$ is the intensity score. This measure hence indicates the percentage at which the current level of input is used relative to the full capacity output level of input utilization. As only one output is considered in the following application, the drawback of DEA mentioned by Walden and Kirkley (2000a, 2000b) in the case of multiple-output production is avoided. In this case, radial expansion of measured capacity output $(\theta)$ may not yield the highest level of production because of slacks in the linear programming model. As previously mentioned, our case study deals with a fleet landing only one species and this drawback does not apply to our study.

\section{Return to Scale Analysis}

The measurement of economies of scale is another issue that can be addressed by the DEA approach. It may have serious implications for policy recommendations concerning the optimal scale of the production units and the fleet, especially in a context of common-pool resource exploitation. The return to scale is a measurement of the increase in output relative to a proportional increase in all inputs, evaluated as marginal changes at a point on a production function.

According to the methodology developed by Cooper, Seiford and Tone (2000), two models can be used in order to decompose inefficiencies in the production process and to identify increasing returns to scale. The first model assumes a constant-return-to-scale (CRS) production possibility set, and it is supposed that the radial expansion and the reduction of all observed individuals are possible. The objective of this method is to assess the so-called global technical efficiency. The second, variable-return-to-scale (VRS) model assumes only convex combinations of the observed fishing units in order to assess local pure technical efficiency. As a consequence, if a fishing unit is fully efficient in terms of both methods, it is operating at the most productive scale size. If an individual is efficient with the VRS model but has a low score with the CRS model, the conclusion is that it is harvesting at a locally efficient but not a globally efficient level, due to the scale size of 
the fishing unit. An index of scale efficiency for observed levels of inputs was developed by Cooper, Seiford and Tone (2000) and they suggested the following ratio:

$$
S E=\frac{\theta_{2 c r s}}{\theta_{2 v r s}}
$$

with $S E \leq 1$

The scale efficiency ratio (SE) is not greater than one and fishing units which are efficient both in terms of constant and variable returns to scale have a scale efficiency equal to one.

$\theta_{2 c r s}$ is found from the second capacity model defined by equations 7 to 11 and $\theta_{2 v r s}$ by adding the following convexity constraint to equations 7 to 11 :

$$
\sum_{j=1}^{J} z_{j}=1
$$

The practical implication of imposing variable returns to scale is that it is easier for some observations to be deemed efficient and placed on the frontier, because imposition of the convexity constraint means that the supporting hyperplane does not have to pass through the origin (Charnes et al. 1994).

Forsund and Hjalmarsson (2004) have explored the issue of optimal issues within the DEA model. They demonstrated that the range of optimal scale levels may be extremely wide with both the maximal and minimal output levels as the optimal scale. Inclusion or exclusion of a few vessels may also have a great effect on the set of optimal scale units and their size. The conclusion is that the scale properties revealed by a DEA study are correct in a technical sense, provided the outputs or the inputs are changed in a strictly proportional fashion. 


\section{Empirical Results}

The model specification is applied to the case study in order to give measures of the dispersion of capacity utilization and indicators of efficient and capacity output. We focus in particular on the sensitivity of the results to the inclusion of an increasing number of inputs or observations. The assumption of the scale efficiency of fishing units is tested and stock indexes are included in the model. The level of analysis is either annual or on a monthly basis.

\section{The Data Set}

Different types of data are used in this case study. Log-book information on a trip level basis gives the level of output (kelp landings in $\mathrm{kg}$ ) and the level of the variable input (the number of trips) (Table 1) respectively.

Table 1. Summary Statistics on the Activity and Landings of the Fleet

\begin{tabular}{|c|c|c|c|c|c|}
\hline & 1985 & 1988 & 1992 & 1995 & 1997 \\
\hline Number of Trips & 6296 & 4949 & 4904 & 4040 & 3971 \\
\hline $\begin{array}{l}\text { Average Landings } \\
\text { (Tons) }\end{array}$ & 9.8 & 11.4 & 13.3 & 13.2 & 14.8 \\
\hline $\begin{array}{l}\text { Standard Deviation } \\
\text { (Tons) }\end{array}$ & 6.0 & 6.4 & 7.0 & 7.2 & 8.6 \\
\hline $\begin{array}{l}\text { Minimum Landings } \\
\text { (Tons) }\end{array}$ & 0.4 & 0.2 & 0.2 & 0.6 & 0.0 \\
\hline $\begin{array}{l}\text { Maximum Landings } \\
\text { (Tons) }\end{array}$ & 37.3 & 64.6 & 43.7 & 59.0 & 61.3 \\
\hline
\end{tabular}

Source: Ifremer

National fleet files give the fixed inputs in terms of the vessels' characteristics: vessel length in meters, engine power in $\mathrm{kW}$, tonnage in GRT, hold capacity in cubic meters and the number of cranes, which is linked to the number of crew members. Different other non-continuous indicators such as harvesting areas or seasons could be used. Biological information such as the level of stock biomass is obtained from Ifremer surveys. Selecting the seaweed fishery as a case study is also of interest because of the very high quality of the data base. In a comparison of logbook data and the processors' purchase data, changes in vessel ownership were undertaken to validate information at an individual level. This process reduces the bias of the application of DEA approaches due to noisy data sets (Todd and Holland 2000).

\section{Capacity and Sensitivity Analysis}

The DEA approach was first carried out on the year 1998 as a whole, with all the available data. As indicated in table 2, the observed output for the total fleet is about 40 thousand tons when the efficient production is $15 \%$ higher. However, the capacity output of this fleet is $45 \%$ higher than the current level of landings with 58 thousand tons. Note that this level is theoretical, because it assumes that the level of stock is able to yield the same productivity with an increase in the level of days at sea. 
Table 2. Observed, Efficient and Capacity Output of the Total Fleet

$\begin{array}{r}\hline \text { Observed Output (in tons) } 40,372 \\ \hline \text { Efficient Output (in tons) } 46,496 \\ \text { Capacity Output (in tons) } 58,634 \\ \hline\end{array}$

The results reported in figure 6 indicate that most of the efficient vessels are either landing between 500 and 1000 tons or landing between 1750 and 2400 tons. For other vessels, it is more difficult to reach capacity output, because it requires a significant increase in the number of trips in the fishery. This is logical, as the fishery is seasonal and many vessels do not enter or leave the fishery at the same time.

Figure 6. Observed, Efficient Output Capacity for Individual Vessels

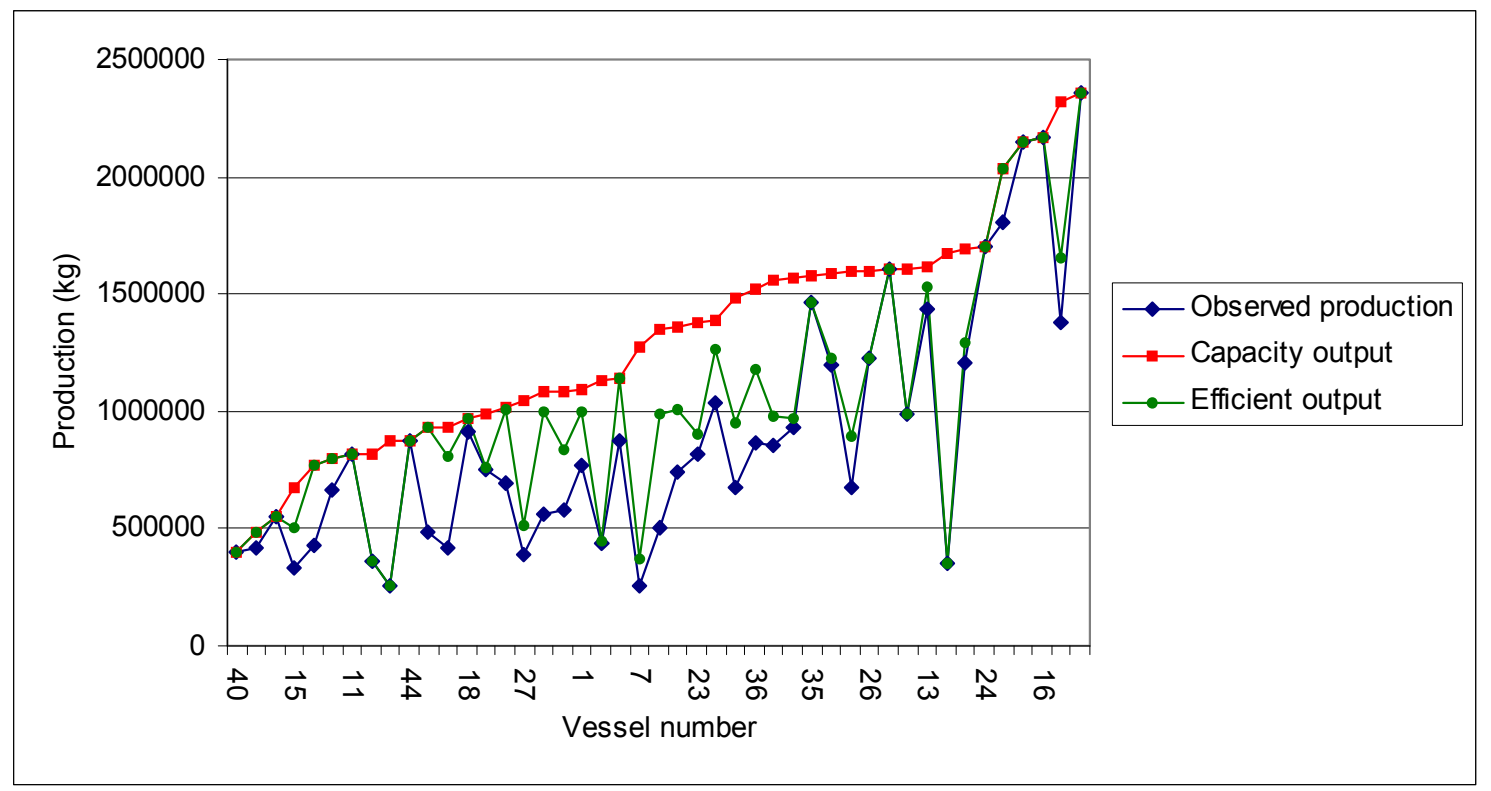

Note: Figures in kg per Vessel

Subsequently, it was required as advised by Cooper, Seiford and Tone (2000) to weight the present results by an analysis of the sensitivity of the results to the inclusion or not of individuals. Table 3 presents the results of the model run either with 29 individuals, or when it is carried out with 45 individuals (including the previous 29 individuals).

Table 3. Sensitivity Analysis of Capacity Utilization (CU) to the Number of Individuals (Year 1998 / 45 vs 29 individuals)

\begin{tabular}{lccc}
\hline Number of Individuals & DEA with 29 Individuals & Difference with 45 Individuals & Deviation \\
\hline Total Capacity Utilization - Technically Efficient & 23.73 & +1.70 & $7 \%$ \\
Total Capacity Utilization - Observed & 20.78 & +2.24 & $11 \%$ \\
\hline
\end{tabular}

Note on Cooper condition

Number of observations $\geq \max (m \times n, 3(m+n))$

With m: the number of outputs and $n$ the number of inputs

In the application: Number of observations $45 \geq 15$ 
The results in table 3 show that the model classically overestimates the CU with a limited number of individuals compared to the results with a larger sample. The deviation is relatively low (7\% and $11 \%$ for Färe CU and observed CU respectively) and the condition of degrees of freedom indicated by Cooper is satisfied. In fact, most of the optimal vessels within the 29 individuals are always optimal with a 45 -individual sample.

As shown in figure 7, the models with only length, length plus number of cranes, and finally all the available fixed inputs, give different results in terms of the technically efficient frontier. They are considered as fixed as they cannot be changed over a short term period by the fishermen. The result is that individual annual production is on the one hand smoothed by the introduction of a higher number of variables and on the other hand reduced for a significant number of fishing units.

Figure 7. Sensitivity of the Technically Efficient Output per Vessel to the Number of Fixed Inputs (year 1998)

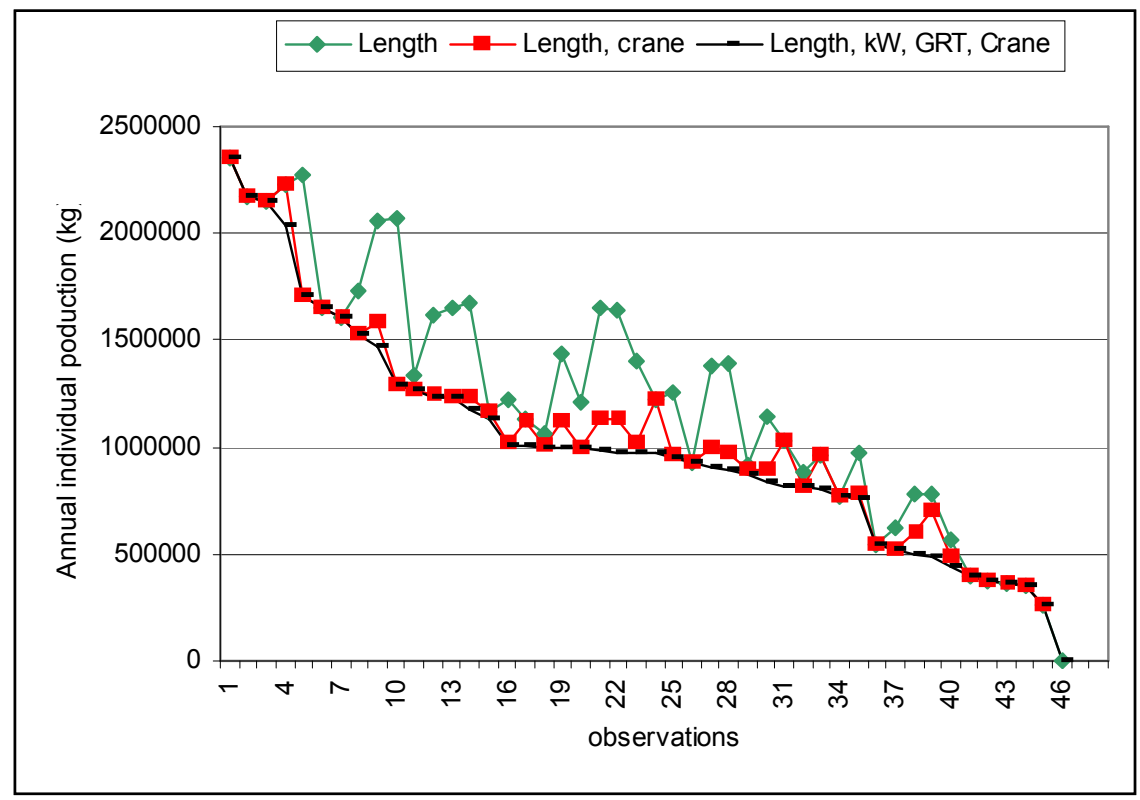

Note: 45 individuals included in the analysis

Moreover, increasing the number of fixed inputs in the analysis increases the number of technically efficient vessels. This number rises from 11 to 16 by this process. The consequence is that withdrawing an input from the analysis likely gives biased results for the technically efficient frontier and then capacity utilization scores. All depends on which variables are binding. If the new additional variables are binding, then there are more segments in the frontier and scores should decline. If the new additional variables are not binding, then there will not be a change in scores. It is also useful to include many measures of inputs in the analysis especially since, with the DEA approach, there isno problem of co-linearity between exogenous variables as in a traditional regression analysis of parametric production functions. 
According to the methodology proposed by Cooper, Seiford and Tone (2000), the empirical results indicate that there are likely increasing returns to scale into this fishery (Figure 8). Within the sample of 45 individuals, only six fishing units are found to be scale efficient even if nine vessels operate near the optimal scale size. As displayed in figure 8 , most of the scale efficient units are the largest vessels landing between 1500 and 2400 tons per vessel. These vessels are, generally speaking, the largest in size (length, $\mathrm{kW}$, number of cranes). The length of these vessels exceeds 10 meters and the number of cranes is 2 for $50 \%$ of these fishing units. The smaller the vessels, the bigger the relative gap between global technical efficiency and pure local efficiency. However, two scale efficient vessels operate at a lower size, around 8.5 meters, with a significant lower production than the largest efficient ones. In this case study, the range of optimal scale levels is extremely wide with both the maximal and minimal output levels as the optimal scale. As described by Forsund and Hjalmarsson (2004), small changes in input ratio could cause large changes in optimal scales.

Figure 8. Distance between the Technically Efficient Output under Variable and Constant Return to Scale

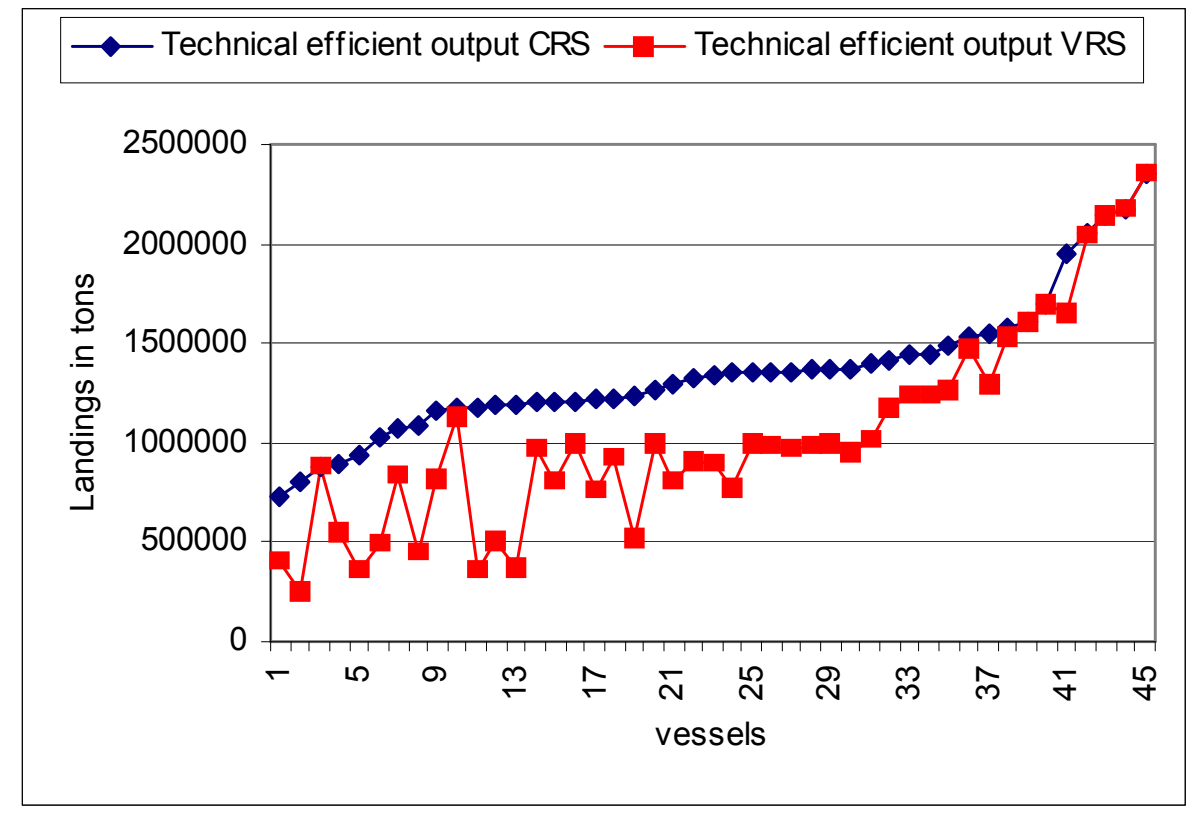

Note: Vessels sorted by increasing output

The regulation limiting the number of trips per day (one per day and per vessel) could explain why the largest vessels are at the optimal scale. These vessels have the greatest hold capacity and consequently are able to spend more time at sea and to harvest more than the smallest vessels in a given trip. The production level of the smallest vessels is consequently more rationed by this regulatory measure than for the largest vessels. When we focus on the two smallest units operating at the optimal scale, it is interesting to underline that both operate in the islands and are not really concerned by the trip regulation. There are able to tranship their production to another conveyor boat when their hold capacity is full. In conclusion, the trip regulation operates as a constraint in production and it may explain why there are incentives to build new vessels or purchase vessels on the second-hand market, with an increasing level of inputs, especially hold capacity.

The analysis of CU scores over a longer period is also of interest in order to examine the impact of the trip regulation on vessels' activity. Before 1987, the number of trips per day was not limited and 
the smallest vessels with the lowest hold capacity could make more than one trip per day. In 1987, the fishermen's organization decided to implement the regulation of "one trip per day" aiming at reducing the impact on the resource. A group of vessels which was active during the 1985-1997 period is selected. The sample comprises 36 fishing units. The annual DEA model gives different indicators like observed, efficient and capacity output as well as capacity utilization scores. As underlined in table 4, the total number of trips and average number of trips per season have decreased due to this regulation (-34\%), falling from 105 trips a year in 1985 to 69 trips, on average, the following years.

Table 4. Observed, Efficient and Capacity Output of the Fleet (Panel Data Set)

\begin{tabular}{lccccc}
\hline & 1985 & 1988 & 1992 & 1995 & 1997 \\
\hline Observed Output (in tons) & 41,767 & 34,371 & 32,413 & 28,146 & 30,076 \\
Output Capacity (in tons) & 53,554 & 43,052 & 41,114 & 36,993 & 41,119 \\
Efficient Output (in tons) & 47,167 & 39,852 & 38,531 & 33,194 & 37,172 \\
& & & & & \\
& 3,782 & 2,669 & 2,644 & 2,283 & 2,352 \\
Observed Number of Trips for the Fleet & 105 & 74 & 73 & 63 & 65 \\
Average Number of Trips per Vessel & 105 & & & & \\
\hline
\end{tabular}

The consequence is a decline in total observed output $(-25 \%)$ and the fall for capacity output and efficient output reaches $-24 \%$ and $-21 \%$ respectively, when we compare the situation before and after regulation. Fishermen have partially compensated for the trip regulation by loading more kelp on their vessels, which explains why the reduction in observed output is less than proportional to the decline in trips. However, analysis of the relative difference between observed output and efficient output shows that the gap has increased over the period (from less than $3 \%$ in 1988 to nearly $10 \%$ in 1997). This probably means that heterogeneity in fleet characteristics has increased with a small number of vessels benefiting from an improvement in fixed input to produce more efficiently, and others not. Conversely, the behavior of fishermen in terms of number of trips was less homogenous before the regulation. As a consequence, the relative difference between capacity output and efficient output is lower after regulation as most of the fishermen have around the same level of activity, especially during the summer season.

As reported in table 5, the average value of $(\lambda>1)$, the utilization rate of the variable input, indicates that, on average, the fleet did not make as many trips into the fishery, especially in 1985.26 vessels had a shortage in the number of trips, which can be explained since each model is annual. The calculation is based on the radial expansion of the variable factor, which is high for some vessels for this year. On the other hand, sensitivity of the variable factor from one year to another can be explained by the entry and exit strategy of each vessel in the fishery over the season.

Table 5. Variable Input Utilization Rate over the Reference Period (Panel Data Set)

\begin{tabular}{rrrrrr}
\hline & 1985 & 1988 & 1992 & 1995 & 1997 \\
\hline Number of Observations Used & 36 & 36 & 36 & 36 & 36 \\
Variable Input Utilization Rate for the Fleet & 43.17 & 40.08 & 43.86 & 41.62 & 42.27 \\
Average per Vessel $(\lambda)$ & 1.20 & 1.11 & 1.22 & 1.16 & 1.17 \\
Number of Vessels $\lambda<1$ & 2 & 6 & 11 & 10 & 7 \\
Number of Vessels $\lambda>1$ & 26 & 19 & 16 & 18 & 21 \\
Number of Vessels $\lambda=1$ & 8 & 11 & 9 & 8 & 8 \\
\hline
\end{tabular}

Note: $\lambda$ as Input utilization rate of the variable factor (see equation 13) $\lambda<1$ excess number of trips. $\lambda>1$ shortage in number of trips 
In all, the level of activity can be considered as relatively high and not far from the maximum level in terms of capacity.

Table 6. Statistics on Capacity Utilization (CU) Scores

\begin{tabular}{lccccc}
\hline Year & 1985 & 1988 & 1992 & 1995 & 1997 \\
\hline Number of Observations & 36 & 36 & 36 & 36 & 36 \\
Fare CU (Average) & $\mathbf{0 . 8 6}$ & $\mathbf{0 . 9 1}$ & $\mathbf{0 . 9 3}$ & $\mathbf{0 . 8 8}$ & $\mathbf{0 . 8 9}$ \\
Fare CU (S.D.) & $\mathbf{0 . 1 8}$ & $\mathbf{0 . 1 5}$ & $\mathbf{0 . 1 7}$ & $\mathbf{0 . 2 2}$ & $\mathbf{0 . 2 1}$ \\
Fare CU (Minimum) & 0.30 & 0.37 & 0.06 & 0.09 & 0.07 \\
Fare CU (Maximum) & 1.00 & 1.00 & 1.00 & 1.00 & 1.00 \\
Observed CU (Average) & $\mathbf{0 . 7 5}$ & $\mathbf{0 . 7 7}$ & $\mathbf{0 . 7 7}$ & $\mathbf{0 . 7 3}$ & $\mathbf{0 . 7 1}$ \\
Observed CU (S.D.) & $\mathbf{0 . 2 3}$ & $\mathbf{0 . 2 2}$ & $\mathbf{0 . 2 2}$ & $\mathbf{0 . 2 6}$ & $\mathbf{0 . 2 4}$ \\
Observed CU (Minimum) & 0.30 & 0.34 & 0.06 & 0.09 & 0.07 \\
Observed CU (Maximum) & 1.00 & 1.00 & 1.00 & 1.00 & 1.00 \\
\hline \multicolumn{4}{c}{ Note: S.D. for Standard Deviation }
\end{tabular}

The observed level of capacity utilization not corrected for technical efficiency is relatively constant over the period (Table 6) and ranges from 0.71 to 0.77 with a low level of dispersion (see annex for graphical distribution). The unbiased level of $\mathrm{CU}$ reaches a minimum of 0.86 for 1985 to a maximum of 0.93 for 1992. As a consequence, there is an opportunity to increase the level of landings ( $+8 \%)$, but probably by adjusting the fishing effort to the evolution of the growth of stock within the season.

\section{Concluding Remarks}

The main results of this study can be underlined from different point of views: methodological and empirical. The indicators provided by the model - observed capacity utilization or unbiased capacity utilization - give measures of the necessary shifts in variable inputs (days at sea) to reach the individual vessel capacity output. The required increase in variable input, which is malleable on a short term basis, is limited because the capacity utilization is quite high within this fleet. It could be difficult to increase vessel activity because the fishery is seasonal and the decision of fishermen to enter or to leave the fishery depends on the economic situation of other fisheries. Moreover, the kelp stock is subject to growth over the season and the increase in capacity output probably needs a monthly adjustment of the fishing mortality to the growth capacity of the stock, rather than an overall increase in the fishing effort. A total allowable catch (TAC) per month should be established to organize this adjustment.

Analysis of scale efficiency with the DEA approach shows that either large vessels or a few small vessels operate at the optimal scale. This is not surprising according to recent studies demonstrating that the range of optimal scale levels may be extremely wide with both the maximal and minimal output levels as the optimal scale (Forsund and Hjalmarsson 2004). In this case study, the optimal scale seems to be influenced by the regulatory measures, especially the number of trips. The number of trips is limited to one per day and this measure benefits the largest units, i.e. those with the greatest hold capacity. The case of the few smallest vessels is specific, as they are not concerned by this regulation. Such a regulation is questionable in the case of this fishery and for different reasons. Boncoeur and Alban (2004) show that the viability of the smallest is threatened by this regulation and the allocation of individual quotas could improve their situation by increasing their 
revenues. As discussed above, the trip regulation gives fishermen incentives to buy or build large vessels in order to benefit from efficiencies of scale. The main problem is that these vessels are not able to operate in a large majority of kelp fields which are not deep enough for the draft of the fishing vessels. Concentration of the capacity within the main areas could lead to a reduced level of production as a whole. As a conclusion, the allocation of individual quotas could benefit the fishery by reducing the "race for kelp" and the incentives to increase vessel size. Moreover, this fishery can be considered as a good candidate for individual quotas as all the landings are purchased and weight by the processors. This reduces the problem of "quota busting" or cheating behavior that generally circumvents the benefits of such a system. 


\section{References}

Arzel, P. 1998. Les Laminaires sur les côtes bretonnes : évolution de l'exploitation et de la flottille de pêche, état actuel et perspectives, Editions Ifremer, Brest, France.

Boncoeur, J. and F. Alban. 2004. Regulatory Measures and Economic Performance of the Seaweed French Fleet, forthcoming in Aquatic Living Resources.

Charnes A., W.W. Cooper and E. Rhodes. 1978. Measuring the Efficiency of Decision Making Units. European Journal of Operational Research 2: pp. 429-444

Charnes A., W.W. Cooper, A.Y. Lewin and L.M. Seiford (eds.) 1994. Data Envelopment Analysis: Theory, Methodology and Applications. Kluwer Academic Publishers.

Coelli, T., D.P. Rao and G. Batteese. 1999. An Introduction to Efficiency and Productivity Analysis. London, Kluwer Academic Publishers.

Cooper, W.W., Seiford, L.M and K. Tone. 2000. Data Envelopment Analysis: a comprehensive text with models, applications, references and DEA-solver software. Kluwer Academic Publishers, USA.

Färe, R., S. Grosskopf and E. Kokkenlenberg. 1989. Measuring Plant Capacity Utilization and Technical Change: A Non-parametric Approach. International Economic Review, 30: pp. 655-666.

Färe, R., S. Grosskopf and C.A.K. Lovell. 1985. The Measurement of Efficiency of Production. Boston, Kluwer Academic Publishers.

Färe, R., S. Grosskopf and C.A.K. Lovell. 1994. Production Frontiers. New York, Cambridge University Press.

Färe, R., S. Grosskopf, J.E. Kirkley and D. Squires. 2000. Data Envelopment Analysis (DEA): A Framework for Assessing Capacity in Fisheries When Data are Limited". IIFET 2000 Proceedings, Oregon State University.

Farrell, M. 1957. The Measurement of Productive Efficiency. Journal of the Royal Statistical Society Series A: General, 120: pp. 253-281.

Forsund, F.R. and L. Hjalmarsson. 2004. Are all Scales Optimal in DEA? Theory and Empirical Evidence. Journal of Productivity Analysis, 21: pp. 25-48

Frost, H. Bergholt, M. Buisman, E. Cupo, P. Daures, F. Davidse, W. Guyader, O. Hatcher, A., Hoefnagel, H. Jensen, C. Jensen, F. Kalaydjian, R. Malvarosa, L. and V. Placenti. 2001. The Significance of Economic Incentives in Fisheries Management under the CFP. Report $\mathrm{n}^{\circ} 127$, Statens Jordbrugs-og Fiskeriokonomiske Institute. 
Gordon, H.S. 1954. Economic theory of a common property resource: the fishery. J. Political Econ. 62: 124-42.

Greboval, D. and G. Munro. 1997. Overcapitalization in World Fisheries: Underlying Economics and Methods of Control. Food and Agriculture Organization of the United Nations, Rome.

Hatcher, A., and K. Robinson (eds.) 1998. Overcapacity, Overcapitalisation and Subsidies in European Fisheries, Proceedings of the first Concerted Action Workshop on Economics and the Common Fishery Policy, UK, 28-30 October, CEMARE Miscellaneous Publication n44 1999, vi+282p.

Holden, M. 1994. The Common Fisheries Policy: Origin, evaluation and future. Fishing News Books, 1994.

Johansen, L. 1968. Production Functions and the Concept of Capacity. Recherches Recentes sur le Fonction de Production, Collection, Economie Mathématique et Econométrie, Vol. 2.

Kirkley, J. and D. Squires. 1999. Measuring Capacity and Capacity Utilization in Fisheries, in D. Greboval, ed., Managing Fishing Capacity: Selected Papers on Underlying Concepts and Issues. FAO Fisheries Technical Report 386. Rome: Food and Agriculture Organization of the United Nations.

Segerson, K. and D. Squires. 1990. On Measurement of Economic Capacity Utilization for Multiproduct Industries. Journal of Econometrics, 75: pp. 76-85

Todd L., S., and D. Holland. 2000. The impact of noisy catch data on estimates of efficient output derived from DEA and stochastic frontier models: a Monte Carlo Comparison. In proceedings of the IIFET2000 conference, Corvallis, USA.

Townsend, R.E. 1985. On Capital Stuffing in Regulated Fisheries. Land Economics 61:195-197.

Vestergaard, N. Hoff, A. Andersen, J. Lindebo, E. Gronbaek, L. Pascoe, S. Tingley, D. Mardle, S. Guyader, O., Daurès F., Van Hoof L, De Wilde J. W. and J. Smit. 2002. Measuring Capacity in Fishing Industries using the Data Envelopment Analysis (DEA) Approach, Department of Environmental and Business Economics, University of Southern Denmark and the authors, ISBN 87-90872-05-03, 271p.

Walden, J.B. and J.E. Kirkley. 2000a. Measuring Technical Efficiency and Capacity in Fisheries by Data Envelopment Analysis Using the General Algebraic Modeling System (GAMS): A Workbook. NOOA Technical Memorandum NMFS-NE-160.

Walden, J.B. and J.E. Kirkley. 2000b. Measuring Capacity of the New England Otter Trawl Fleet. IIFET 2000 Proceedings, Oregon State University. 
Figure 9. Distribution of Observed Capacity Utilization Scores per Year

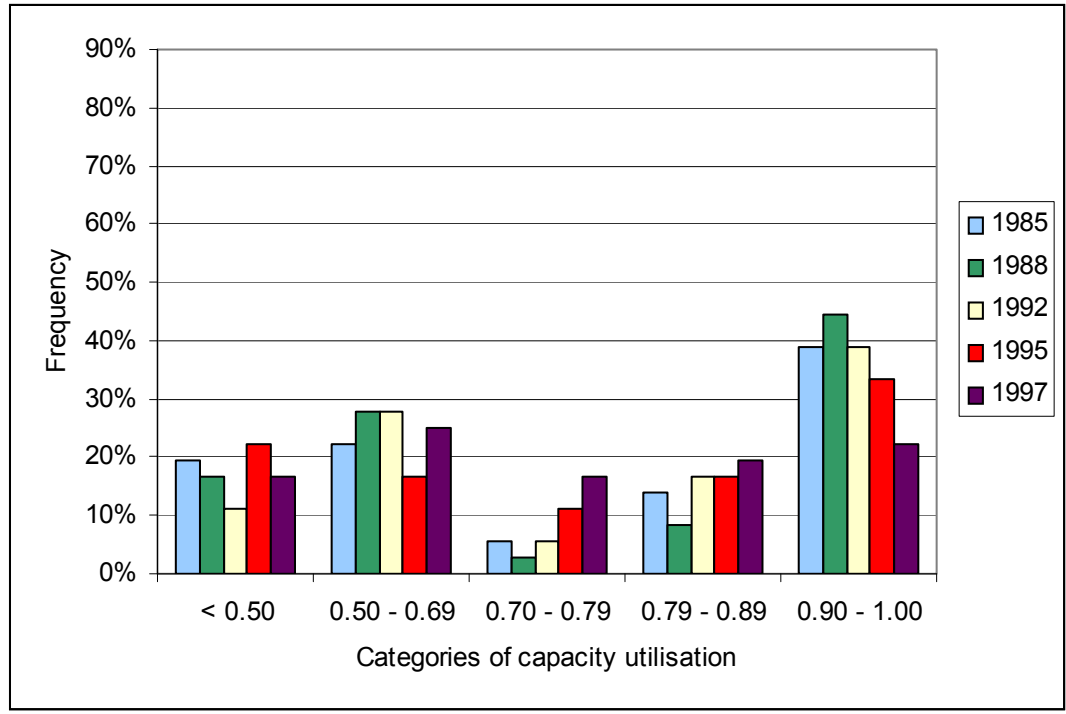

Figure 10 Distribution of Färe Capacity Utilization Scores per Year

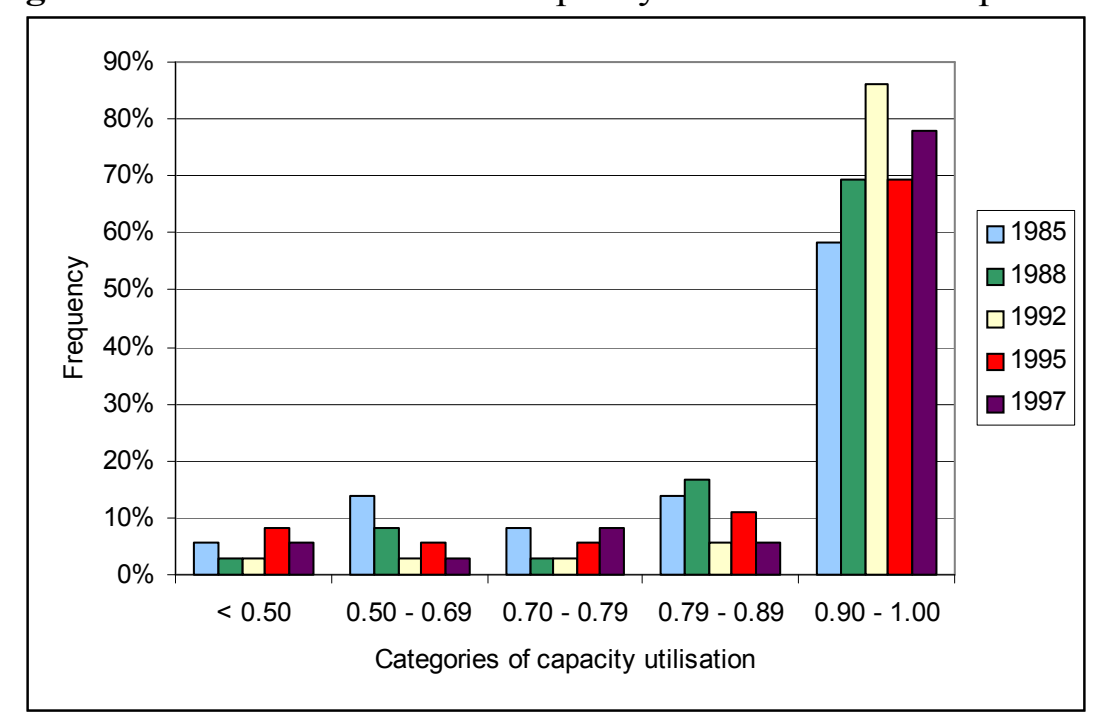

